\title{
A voz do protagonista afrodescendente em romances históricos hispano-americanos: invisibilidade do texto original e algumas (poucas) obras traduzidas no Brasil
}

\author{
Liliam Ramos da Silva (UFRGS)
}

\begin{abstract}
Resumo: Opresente artigo refletirá sobre o insuficiente número de obras traduzidas no Brasil, publicadas no âmbito bispano-americano, que tratam da questão afrodescendente. A análise partirá dos resultados parciais da pesquisa "Vozes negras no romance hispano-americano", cujo objetivo é investigar os romances que apresentem protagonistas negros e analisá-los com relação às suas atitudes e perspectivas na sociedade escravocrata, de que maneira (re)escrevem as histórias da escravidão nas Américas a partir do seu lugar de enunciação e como apresentam-se os vestígios recuperados das memórias da cultura afrodescendente. Na primeira etapa da pesquisa, foram listados os romances com protagonistas negros; na segunda, será elaborada uma tabela com os dados dos romances encontrados, incluindo suas traduções no Brasil; na terceira os romances serão analisados pelo grupo, inclusive na perspectiva comparada de tradução.
\end{abstract} Palavras-chave: Protagonista afrodescendente. Romance bistórico bispano-americano. Tradução no Brasil.

\section{Preliminares}

As décadas finais do século XX foram frutíferas no avanço dos estudos da cultura afrodescendente nas Américas e percebe-se que este é um campo que tende a aumentar cada vez mais devido ao crescente número de publicações, congressos, simpósios, encontros, etc. dedicados à leitura e discussão de obras

1 Professora de tradução espanhol-português, língua espanhola e suas respectivas literaturas na Universidade Federal do Rio Grande do Sul; doutoranda em Literaturas Estrangeiras Modernas - ênfase espanhol - na mesma universidade; coordenadora da pesquisa "Vozes negras no romance hispano-americano". Contato: liliam.ramos@ufrgs.br 
literárias cujo contexto resgata a(s) história(s) da escravidão no continente. A pesquisa "Vozes negras no romance hispano-americano", desenvolvida desde o ano de 2012 no Instituto de Letras da Universidade Federal do Rio Grande do Sul, tenta preencher o espaço vazio imposto pela História oficial ao rastrear os romances escritos nos países hispano-americanos que contenham personagens negros como protagonistas e analisá-los com relação às suas atitudes e perspectivas na sociedade escravocrata, de que maneira (re)escrevem as histórias da escravidão nas Américas a partir do seu lugar de enunciação e, também, como apresentam-se os vestígios resgatados das memórias da cultura afrodescendente nos romances.

Além da pesquisa com o texto original e pensando em sua circulação no âmbito editorial, pesam sobre os pesquisadores algumas questões: se a divulgação dos originais desses textos, romances publicados em diferentes épocas e editoras de países hispano-americanos ou na Espanha, é considerada insuficiente nos países latino-americanos (pois parece que há uma barreira editorial entre a América hispânica e o Brasil) e entre os próprios hispano-americanos, quais efetivamente são considerados importantes a ponto de serem traduzidos em nosso país? O que chega à luso-América relativo à escravidão nos países hispano-americanos? Estas perguntas tentarão ser respondidas na presente reflexão. Neste momento, não se trata de um estudo analítico e sim informativo ao público leitor que se interessa pelo gênero romance histórico que contextualiza o momento histórico da escravidão africana e que apresenta protagonistas negros, independentemente da cor da pele dos escritores ou do seu envolvimento com movimentos negros.

\section{(Re)lendo a história da escravidão na América Hispânica}

Para Aguirre (2005), a proclamação da República Negra do Haiti - que retoma o nome original da ilha antes da chegada dos europeus (Haiti: terra de montanhas) - apresentou um caráter radicalmente revolucionário. A construção de um espaço no qual todos os habitantes fossem considerados cidadãos, independente da cor da pele, era novidade no mundo moderno de então, inclusive na África. Os negros do Novo Mundo colocam em questão a exploração de seres humanos e também todo um sistema mental e até filosófico que guiava os intelectuais da época: o de que a população negra estaria condenada a servir a sociedade branca dominante e que a escravidão das pessoas de cor mais escura era natural, sancionada pelos costumes, pela lei e pela religião. No entanto, tal fato está até hoje sistematicamente excluído dos manuais de história e não é trabalhado este momento histórico na educação básica. 
Segundo Klein e Vinson III (2008), as diferentes opiniões em relação à instituição escravocrata percorrem a época do Iluminismo na França: a publicação da Enciclopédia de Diderot y D'Alembert (obra coletiva que pretendia compilar o pensamento ilustrado e na qual participaram os grandes pensadores da época, como Montesquieu, Voltaire e Rousseau) estabelece a contradição em que viviam esses intelectuais. Se, por um lado, a maior parte reprovava e condenava a escravidão dos seres humanos, Montesquieu, por exemplo, tinha uma posição abertamente racista e depreciativa com relação aos negros. Tais paradoxos pareciam ser comuns naquele momento histórico: outro exemplo é a primeira declaração de direitos de uma colônia norte-americana - Virginia - que, em 1776, expressava que "todos os homens são por natureza igualmente livres e independentes”, afirmação que, naturalmente, excluía os negros escravos. A própria abolição da escravidão no Haiti, proclamada em 1794 e reestabelecida por Napoleão em 1804, somente teria seu final em 1848, o que demonstra que o processo foi burocrático e lento já que modificaria completamente as relações humanas da época.

A revolução dos escravizados no Haiti, no âmbito literário, proporcionou aos escritores material abundante devido à sua história maravillosa resgatada primeiramente por Alejo Carpentier em El reino de este mundo (1949), proposta seguida pelo colombiano Manuel Zapata Olivella em Changó, el gran putas (1984) e, recentemente, sob um ponto de vista feminino, por Isabel Allende em La isla bajo el mar (2009). Dessas três obras, duas possuem traduções no Brasil: O reino deste mundo teve sua primeira tradução na versão de João Olavo Saldanha em 1985 pela Civilização Brasileira e a segunda versão, de Marcelo Tápia, foi publicada em 2010 pela Martins Fontes. Já $A$ ilha sob o mar foi lançada no Brasil um ano após sua publicação em Buenos Aires pela Sudamericana; aqui, o responsável pela tradução foi o gaúcho Ernani Ssó e a publicação saiu pela Bertold Brasil em 2010.

De acordo com Enio Vieira em texto veiculado pela Revista Bula (2008), somente os autores hispano-americanos considerados medalhões como Mario Vargas Llosa, Gabriel García Márquez, Jorge Luis Borges, Julio Cortázar entre outros incluídos no boom literário (editorial?) dos anos 60 do século XX, seguem publicando e acabam ocupando todos os espaços nos meios de comunicação do Brasil:

Para conhecer literatura hispano-americana, o leitor brasileiro ainda depende de escolhas feitas pelas editoras de grandes centros globais. Um autor argentino, mexicano ou caribenho estará disponível no Brasil após a chancela de quem edita livros em Nova York, Londres, Paris e Madri. É a lógica da triangulação das trocas econômicas. Há as exceções de praxe, mas 
uma obra de um país vizinho precisa atravessar oceanos para depois chegar às prateleiras das livrarias brasileiras (VIEIRA, 2008, s/p).

Entre os medalhões, Vieira destaca os nomes de Isabel Allende e Alejo Carpentier, citados anteriormente. Embora não sejam autores afrodescendentes, suas obras têm alcance mundial e, de certa forma, acabam levando histórias da escravidão hispano-americana a um grande público que consome sua literatura principalmente a de Allende, considerada uma escritora de massas. Contestada na academia por ser uma vendedora de livros cujos textos mantem os clássicos efeitos narrativos e que pouco contribui para os estudos literários, o crítico peruano José Miguel Oviedo (2012) a defende, afirmando que Allende é um modelo novelístico que muitos autores tratam de seguir graças à sua habilidade para elaborar uma versão bastante pessoal de fórmulas já provadas; sua perspectiva histórica sob a voz de uma protagonista mulher tem seu público fiel.

A publicação de El reino de este mundo marca um momento importante na literatura hispano-americana e mundial: ao (re)contar a história da revolução dos escravizados que resultou na primeira (e única) República Negra das Américas, o autor resgata os valores culturais dos africanos ressignificando símbolos após uma viagem ao Haiti. Ao descrever o termo real maravilloso como um conceito chave das Américas, exemplificado através do vodu, o autor faz uma interpretação ativa e consciente da realidade hispano-americana, formada pelas diversas identidades dos habitantes do continente. Com destaque para a identidade afro, o autor afirma que os escravizados trouxeram uma cultura proliferante, uma religião viva, que se mistura às práticas europeias e indígenas realizadas no espaço americano formando, assim, uma prática transcultural, única e, ao mesmo tempo, composta por múltiplas contribuições de diferentes indivíduos e realidades culturais.

A revolução haitiana também aparece como pano de fundo no romance La isla bajo el mar, de Allende. A protagonista - uma mulher negra e escravizada - luta para conseguir sua liberdade e poder estar com sua família. A escritora põe em pé de igualdade os discursos histórico e mítico ao recontar a morte do escravo Mackandal: para os brancos (discurso histórico), o feiticeiro tem seu corpo queimado em praça pública. Para os escravizados (discurso mítico), Mackandal se transformou em mosquito e até hoje sobrevoa os céus do Haiti, incentivando a luta dos habitantes deste país contra as catástrofes sociais e climáticas, contra o racismo e a segregação.

Vieira, em 2008, afirmava que estavam chegando bons textos da Colômbia ao mercado editorial brasileiro e cita nomes como Fernando Vallejo e Efraín Medina Reyes. Curiosamente, um grande nome da literatura colombiana que 
despontava no cenário literário colombiano é deixado de lado: Manuel Zapata Olivella (1920-2004). A família Zapata Olivella (Manuel e seus irmãos Juan e Delia) privilegiaram a voz afro-colombiana em poesias, novelas, ensaios e centros folclóricos de resgate da cultura afrodescendente. Manuel Zapata Olivella é o autor da grande obra da literatura afro-colombiana - e por que não dizer da literatura afro-hispano-americana - intitulada Changó, el gran putas. Considerada a saga da negritude em terras colombianas (e americanas em geral, pois abrange todos os países que passaram pela experiência de um sistema escravista), apresenta como tema a diáspora do povo africano nas Américas e a formação da cultura afro-hispano-americana.

No Brasil, o material que chegou ao público leitor relacionado à produção de Zapata Olivella é o livro Manuel Zapata Olivella e o "escurecimento da literatura latino-americana", de Antonio D. Tillis, publicado pela Editora da UERJ. Na obra, o professor e pesquisador do Dartmouth College na Carolina do Sul (EUA) elabora textos críticos sobre algumas obras ficcionais de Zapata Olivella e também sobre um ensaio (Las claves mágicas de América Latina) e, ao final, propõe trechos de tais obras traduzidos ao português. Atualmente, um grande número de pesquisadores brasileiros se debruça em pesquisas sobre sua vasta obra, tão relevante para os estudos étnicos nas Américas ${ }^{2}$. No entanto, não parece haver movimentação para a tradução de suas obras completas no país.

\section{O protagonismo negro em romances do século XIX}

Segundo estudos sobre a questão afrodescendente, o negro em terras hispânicas praticamente não teve destaque nos estudos identitários. Após as independências, com a afirmação dos países enquanto nação, os escritores se preocupam em resgatar os valores indígenas, já que alguns países exterminaram ou expulsaram dos centros urbanos os negros escravos na época das abolições (pois estes já não tinham mais serventia e os senhores preferiram pagar - pouco - aos imigrantes europeus, inclusive pela questão do branqueamento da população). O negro dos primeiros romances aparece demostrando muita força, mas pouca inteligência. De acordo com Gonçalves (2004), por exemplo, os primeiros romances anties-

2 Orientada pela Profa. Dra. Zilá Bernd, a autora deste artigo foi a primeira pesquisadora brasileira a defender um trabalho acadêmico analisando a obra Changó, el gran putas no Brasil. Referência: SILVA, Liliam R. (Re)contando a história: a (re)construção da identidade negra em Viva o Povo Brasileiro e Changó, el gran putas. Dissertação de Mestrado. Porto Alegre: PPG/Letras/UFRGS, 2005. Disponível em < http://www. lume.ufrgs.br> 
cravistas cubanos do século XIX não tinham a preocupação de mostrar nenhum tipo de rebeldia ou resistência; pelo contrário, sugeriam que esse escravo não tinha o desejo de liberdade e aceitava passivamente seu destino. Percebe-se, então, a representação estereotipada do negro que - maculada pela perspectiva estética do branco/ocidental - deseja "copiar" essa cultura, tornando-se igual ao sujeito "superior", aceitando a condição inferior que lhe é atribuída. O personagem aparece, na literatura, descrito como dócil, submisso e resignado à sua sorte.

A partir do século XX - com as concepções de resgate de histórias silenciadas e/ou esquecidas, alguns escritores e teóricos latino-americanos publicam escritos sobre a questão dos negros em terras hispânicas. Surge, então, nos anos 1930, elaborado por intelectuais antilhanos, e impulsionados pelo negrismo europeu, o conceito de negritude, que faz com que os negros passem a aceitar suas raízes e ter orgulho delas através de sua autoafirmação perante um pensamento ocidental que nunca os havia considerado (SILVA, 2005).

O personagem negro começa a ser retratado na literatura hispano-americana de modo a transmitir o sentimento coletivo de marginalização. A literatura, privilégio da elite letrada, principalmente no que tange ao gênero romance, passa a ganhar espaço entre os excluídos, despertando a voz daqueles que por séculos foram silenciados. De acordo com Burke (1994), o (re)contar da história desponta não somente para narrar os acontecimentos do passado, mas também para trazer à tona personagens (verídicos) excluídos e esquecidos da história oficial. O fenômeno da caracterização do personagem negro, embora pouco recorrente, não é um fato recente nas gerações literárias. O protagonismo negro começou a ser retratado desde a época colonial, manifestando-se, principalmente, em círculos intelectuais de Cuba. Dita literatura era, em grande parte, publicada a partir de encomendas vindas da Europa realizadas por pensadores como Domingo del Monte - crítico literário e criador da Academia de Literatura Cubana. Del Monte e os demais ideólogos abolicionistas da época acreditavam que para solucionar o problema da escravidão era de suma importância que argumentos a favor do antiescravismo viessem também das vítimas. Dessa forma, a criação de tertúlias para discussões sobre a temática emerge de maneira a promover a cultura criolla de raiz africana ${ }^{3}$ altamente influenciada pelos ideais dos intelectuais abolicionistas da Inglaterra e do norte dos Estados Unidos. É nesse contexto que apresenta-se Autobiografía de

3 Saqui (2000) discorre na obra comentada do livro Francisco, el Ingenio o las delicias del campo, de Anselmo Suárez y Romero, a vida do crítico literário Domingo del Monte, bem como de outros pensadores abolicionistas que participavam do mesmo círculo intelectual cubano. 
Juan Francisco Manzano, também referenciada como Autobiografía de un esclavo, obra precursora do gênero testemunho na América hispânica.

Embora as publicações de testemunhos escravistas escritos pelos próprios afrodescendentes fossem incentivadas pelos círculos intelectuais abolicionistas da América do Norte e do Caribe, as Américas hispânica e portuguesa não contaram com o mesmo apoio e, por isso, Autobiografía é o único texto do gênero na América Latina divulgado até hoje. As datas são imprecisas e divergem entre 1835 e 1839 para a publicação em Londres; já a tradução ao espanhol e a recepção em Cuba teriam ocorrido somente no século XX. Texto importante por introduzir à literatura a narrativa antiescravista na perspectiva do escravizado, é um estudo base para as pesquisas em literatura afrodescendente produzidas nas Américas e constantemente citado em artigos sobre esta temática.

Felizmente, no Brasil, está para ser publicada em 2015 a primeira tradução em português da Autobiografía. O escritor e tradutor Alex Castro lançará, pela editora Hedra, o livro A autobiografia do Poeta-Escravo por Juan Francisco Manzano, que apresenta não somente uma tradução do texto como também uma transcriação da obra. O texto traduzido tem como objetivo ser o mais acessível possível a estudantes de nível médio e a população em geral, visto que trata-se de uma escrita do século XIX; já o texto transcriado se propõe a fazer uma tradução literária da autobiografia, mantendo o vocabulário da época e utilizando notas de rodapé para explicar eventuais problemas de compreensão que o leitor possa vir a ter. O leitor brasileiro interessado na ficção sobre o momento histórico da escravidão terá a oportunidade de acessar o testemunho mais conhecido de um escravo hispano-americano que, com a colaboração de um grupo de intelectuais (brancos) consegue, segundo Castro (2015, p. 16, no prelo) produzir um texto cheio de lacunas gritantes, elipses conspícuas e entrelinhas prolixas: "É necessário uma leitura cuidadosa para decifrar seus silêncios", pois, embora os intelectuais estejam por trás, o autor conseguiu produzir um texto híbrido, transculturado, onde pôde, através dos silêncios, fazer ouvirem a sua voz. A decisão pelo título, segundo o professor de História Contemporânea da UNRIO, Ricardo Salles, responsável pelo prólogo, foi a de usar palavras que eram recorrentes à época (autobiografia - poeta - escravo) mas que nunca eram encontradas em um mesmo vocabulário “ficcional, poético, historiográfico e político" (SALLES, 2015, p. 10, no prelo).

\section{Vozes afrodescendentes femininas no século XXI}

A representação do negro surge no século XXI como literatura de ruptura, com a intenção de atribuir voz àqueles que ainda estão à margem da sociedade, 
recriando espaços de miséria, pobreza e exclusão, porém, com o intuito de denunciar o preconceito que percorre os séculos e demonstrar a sua realidade, com suas crenças e costumes, sua maneira diferente de observar o mundo. Buscar esses romances e analisá-los é um método de entender o processo histórico a partir de uma perspectiva literária, de modo que personagens subalternos da história oficial tenham sua vez como protagonistas e possam expressar suas agruras e sofrimentos, (re)contando a sua história de forma a orgulhar-se dela e não se deixar dominar por discursos discriminatórios e preconceituosos.

O século XXI está fecundo no que diz respeito à produção afrodescendente feminina. Novas vozes estão surgindo rompendo com a cultura editorial de privilegiar textos escritos por homens. No Caribe, escritoras como a porto-riquenha Mayra Santos Febres ${ }^{4}$ e a cubana Teresa Cárdenas, afrodescendentes que escrevem sobre a temática reivindicando a voz da mulher negra, estão conquistando um espaço no mercado editorial bastante significativo. No Brasil, Teresa Cárdenas conta com traduções de duas obras: as cartas de uma menina a sua mãe já morta - Cartas para minha mãe, com tradução de Eliana Aguiar em 2011 e o romance histórico Cachorro Velho, traduzido por Joana Angélica D’Ávila Melo, em 2010, ambos pela Editora Pallas. Aliás, é importante dizer que estas são as únicas versões das traduções de romances cujos protagonistas sejam negros e que tratem das vozes negras (outrora silenciadas) publicadas por uma editora reconhecidamente inclusiva, já que permite reservar em seu catálogo uma grande parte direcionada aos temas afrodescendentes. Cárdenas foi vencedora do Premio Casa de Las Américas em 2005 por Cachorro Velho e, por isso, o reconhecimento do mercado editorial brasileiro.

\section{Dados preliminares da pesquisa: publicações e traduções}

Segundo dados preliminares da pesquisa Vozes negras no romance hispano-americano (listagem de obras em anexo), no decorrer do século XIX foram publicados 16 romances que apresentavam protagonistas negros. Destes 16, a produção cubana predomina com 9 textos abolicionistas e, no Brasil, apenas em 2015 será lançada a primeira tradução do primeiro texto publicado: Autobiografia do poeta-escravo por Juan Francisco Manzano. Textos importantes como Sab (1841), de Gertrudis Gómez de Avellaneda e Cecilia Valdę.(1882), de Cirilo Villaverde, referências obrigatórias em pesquisas sobre o tema, parece que ainda não despertaram o interesse em tradutores e/ou editoras brasileiras.

4 Dois romances que apresentam o negro como protagonista: Fe en disfraz (2009) e Nuestra Señora de la Noche (2006). 
No século XX, prolifera-se este tipo de produção literária: serão 37 romances que privilegiarão o protagonismo do negro no romance histórico hispano-americano. A Colômbia passa a ser o país mais representativo deste tipo de produção, com 15 romances, dos quais 10 estarão a cargo dos irmãos Manuel e Juan Zapata Olivella, nenhum deles traduzido no Brasil. Urge a chegada no país de uma tradução do romance do colombiano Roberto Burgos Cantor La ceiba de la memoria (2007), ganhador do Premio Casa de las Américas em 2009, que reconta a história da escravidão no século XVI através do resgate de histórias interiores de cada um dos personagens que fizeram parte daquele momento histórico: o autor, negro, reconstrói a(s) história(s) da escravidão sob o ponto de vista de indivíduos envolvidos no processo: negros e negras escravizados, o padre Pedro Claver, proprietários de escravos, professores pesquisadores, Benkos Biojo - o primeiro líder palenquero das Américas.

Outros países, como Equador e Venezuela, possuem juntos uma considerável porcentagem de romances estudados na pesquisa, porém nenhum deles ainda foi traduzido no Brasil. Uma das escritoras afrodescendentes que mais desponta no mercado editorial mundial é a equatoriana Argentina Chiriboga, a voz negra feminina que já foi traduzida para o inglês e para o italiano ${ }^{5}$.

Nesta época, a região que mais carece de protagonismo negro na literatura é, sem dúvidas, o Cone Sul. O fenômeno da questão negra nesses países é recente, somente no final do século XX e começo do século XXI começou-se a publicar romances referentes ao tema. Frequentemente pensa-se que essa ausência se deve ao fato da inexistência ou escassez de negros nesses países, com o argumento de que a escravidão teria sido mais amena em tal região. De fato, é um equívoco dizer que existe escravidão amena e um engano pensar que não há a presença de negros nesses países. O que esses indivíduos sofrem, na verdade, é de invisibilidade, fato que acarreta na representação desses personagens na literatura.

Os romances históricos que narram a saga de protagonistas negros no século XX traduzidos no Brasil foram as duas produções de Alejo Carpentier Ecue-Yamba-O (1933), com tradução de Mustafa Yazbek publicado somente em 1989 pela Editora Brasiliense e o já citado $O$ reino deste mundo, com suas duas traduções (conforme comentado anteriormente). Entra na lista Memórias de um cimarron (1966), do também cubano Miguel Barnet com tradução de Beatriz A. Cannabrava pela editora Marco Zero em 1986, 20 anos após a publicação do original. À página 7, há uma nota explicativa da tradutora anunciando que foi decidido manter o

5 Como exemplos, podemos citar Bajo la piel de los tambores (1991) e Jonatás y Manuela (1994). 
original cimarron (sem acento) no título por tratar-se de um termo específico, assim como vários outros no decorrer do texto.

No século XXI, até o ano de 2015, foram publicados 21 romances no qual o protagonista é negro. A Argentina desponta com o maior número de publicações (10 no total), em especial as dos escritores Washington Cucurto ${ }^{6}$ e Mirta Fachini ${ }^{7}$, ambos com 3 romances cada. No Brasil, pode-se contar com as já citadas traduções de $A$ ilha sob o mar, de Isabel Allende, as duas obras de Teresa Cárdenas (Cartas para minha mãe e Cachorro Velho) e também com a narrativa longa Coisa de negros, de Cucurto, traduzida em 2007 por André Pereira da Costa para a Rocco. Segundo o crítico literário Joca Reiners Terron, em texto publicado na Folha de São Paulo no mesmo ano do lançamento da tradução no Brasil, tratou-se de um grande desafio para o tradutor ao transpor as gírias "callejeras" presentes na cumbia do subúrbio de Buenos Aires para a linguagem do funk carioca. Cucurto apresenta, portanto, uma outra capital platina, não aquela europeia, desenvolvida e industrializada, e sim a composta pelos imigrantes pobres oriundos principalmente do Paraguai e Peru e seus deslocamentos pelos "arrabales" portenhos, denunciando a situação do afro-argentino que foi excluído da modernização da cidade.

\section{Considerações finais}

Percebe-se que intelectuais hispano-americanos vêm teorizando e pensando as Américas como este espaço de encontros e confrontos. No entanto, ainda são escassos os estudos sobre a participação do negro na história hispano-americana, e menor ainda é o número de escritos de autores negros. Tal ausência se explica por ainda acontecerem em vários países situações de racismo e preconceito contra afrodescendentes, e as ações afirmativas de inclusão da população negra costumam ser inexistentes ou pouco eficientes.

Se existe uma grande dificuldade de circulação de romances originais entre países da própria América hispânica, visto que as editoras que publicam estes textos costumam ser de universidades ou de grupos culturais, ou seja, não são as grandes editoras que sustentam o mercado literário, certamente mais difícil ainda será o ingresso dessas obras traduzidas no Brasil. O conhecimento sobre essas

6 Localizando-se espacialmente e temporalmente nas cidades grandes do fim do século XX, o autor aborda temas da cotidianidade em Cosas de negros e Sexibondi (ambos publicados em 2003). Porém também flerta com o romance histórico em 1810. La revolución vivida por los negros (2008).

7 Com um tom mais místico, resgatado das memórias africanas passadas de geração em geração, publica El espiritu oculto em 2012. Herencia negada e Susurros negros são ambos de 2014. 
obras acaba se dando em viagens e participações em seminários in loco, muitas vezes sendo bastante difícil encontrar esses textos em livrarias no próprio país de publicação.

O mercado editorial, portanto, ao privilegiar a comercialização de obras traduzidas de autores mundialmente reconhecidos, priva o leitor de conhecer a produção literária afrodescendente desenvolvida nos países vizinhos, fazendo com que a invisibilidade dessas obras seja o motivo pelo qual pouco se conhece sobre esses textos e com que haja uma falsa impressão de que este tipo de produção não é recorrente nos países hispano-americanos.

\section{Referências bibliográficas}

\section{Romances citados}

ALLENDE, Isabel. La isla bajo el mar. Buenos Aires: Sudamericana, 2009.

BARNET, Miguel. Memorias de un cimarrón. La Habana: Instituto de Etnología y Folklore, 1966.

BURGOS CANTOR, Roberto. La ceiba de la memoria. Bogotá: Editorial Planeta Colombiana, 2007.

CÁRDENAS, Teresa. Cartas a mi mamá. La Habana: Fondo Editorial Casa de las Américas, 2005.

. Perro Viejo. Fondo Editorial Casa de las Américas, 2005.

CARPENTIER, Alejo. Ecue-Yamba-O. Madrid: Editorial España, 1933.

. El reino de este mundo. Caracas: Primer Festival del Libro Popular Venezolano, 1949.

CHIRIBOGA, Argentina. Jonatás y Manuela. Quito: Editorial de la Casa de la Cultura Ecuatoriana Benjamin Carrión, 1994.

Bajo la piel de los tambores. Quito: Editorial de la Casa de la Cultura Ecuatoriana Benjamin Carrión, 1991.

CUCURTO, Washington. 1810. La revolución vivida por los negros. Buenos Aires: Emecé Editores, 2008. . Cosa de negros. Buenos Aires: Interzona, 2003. . Sexibondi. Buenos Aires: Interzona, 2003.

FACHINI, Mirta. Herencia negada. Córdoba: Emporio Ediciones, 2014. . Susurros negros. Córdoba: Emporio Ediciones, 2014. . El espíritu oculto. Córdoba: Ediciones del Boulevard, 2012.

GÓMEZ DE AVELLANEDA, Gertrudis. Sab. Madrid: Imprenta Calle del Barco núm. $26,1841$. 
SANTOS-FEBRES, Mayra. Fe en disfraz. Penguim Random House, 2009. . Nuestra Señora de la Noche. Madrid: Espasa, 2006.

VILLAVERDE, Cirilo. Cecilia Valdés o la loma del ángel. La Habana: Ediciones Huracán, 1882. ZAPATA OLIVELLA, Manuel. Changó, el gran putas. Bogotá: Editorial Oveja Negra, 1983. . Las claves mágicas de América. Raza, classe y cultura. Bogotá: Plaza \& Janés, Editores Colombia Ltda., 1989.

\section{Romances traduzidos}

ALLENDE, Isabel. A ilha sob o mar, tradução de Ernani Ssó. São Paulo: Bertrand Brasil, 2010.

BARNET, Miguel. Memórias de um cimarron, tradução de Beatriz A. Cannabrava. São Paulo: Marco Zero, 1986.

CARDENAS, Teresa. Cartas para mina mãe, tradução de Eliana Aguiar. Rio de Janeiro: Pallas, 2010.

. Cachorro velho, tradução de Joana Angélica D’Ávila Melo. Rio de Janeiro: Pallas, 2011.

CARPENTIER, Alejo. O reino deste mundo, tradução de Marcelo Tápia. São Paulo: Martins Fontes, 2010.

. O reino deste mundo, tradução de João Olavo Saldanha. São Paulo: Civilização Brasileira, 1985.

. Ecue-Yamba-O, tradução de Mustafa Yazbek. São Paulo: Brasiliense, 1989.

CUCURTO, Washington. Coisa de negros, tradução de André Pereira da Costa. São Paulo: Rocco, 2007.

\section{Teórico-crítica}

AGUIRRE, Carlos. Silencios y ecos: La historia y el legado de la abolición de la esclavitud en Haití y Perú. In: Revista A Contracorriente, v. 3, n. 1, 2005. p. 3-37.

BURKE, P. (Org.). A escrita da História: novas perspectivas. São Paulo: UNESP, 1994.

CASTRO, Alex. A autobiografia do poeta-escravo por Juan Francisco Manzano. São Paulo: Hedra, 2015 (no prelo).

GONÇALVES, Ana Beatriz. Estudos afro-hispano-americanos: uma problemática. Página eletrônica: www.letras.ufmg.br/espanhol/Anais/anais.../Estudos\%20afro-hispano.pdf. Consulta realizada em 09 de março de 2011.

KLEIN, Herbert e VINSON III, Ben. La esclavitud africana en América Latina y el Caribe. Traducción de Graciela Sylvestre Sánchez Albornoz. Lima: Instituto de Estudios Peruanos, 2008. 
OVIEDO, José Miguel. Historia de la literatura hispanoamericana. De Borges al presente. v. 4. Madrid: Alianza Editorial S.A, 2012.

SALLES, Ricardo. Prefácio. In: CASTRO, Alex. A autobiografia do poeta-escravo por Juan Francisco Manzano. São Paulo: Hedra, 2015 (no prelo). p. 9-12.

SAQUI, Mario Cabrero. Francisco. El ingenio o las delicias del campo / Anselmo Suárez y Romero; edición prologada y anotada. Alicante: Biblioteca Virtual Miguel de Cervantes, 2000. Página eletrônica: http://www.cervantesvirtual.com/obra-visor/francisco-el-ingenio-o-las-delicias-del-campo--0/html/ff20adea-82b1-11df-acc7-002185ce6064 1.htm. Consulta realizada em 31 de maio de 2014.

TERRON, Joca Reners. "Cucurto põe a alta literatura para dançar no chão". In: Folha de São Paulo. 29/09/2007. Página eletrônica: http://www1.folha.uol.com.br/fsp/ilustrad/ fq2909200723.htm. Consulta realizada em 18 de outubro de 2015.

TILLIS, Antonio D. Manuel Zapata Olivella e o "escurecimento" da literatura latino-americana., tradução de José Paiva dos Santos. Rio de Janeiro: EdUERJ, 2012.

VIEIRA, Enio. “América Nuestra”. In: Revista Bula. 10/03/2008. Página eletrônica: http: $\angle$ acervo.revistabula.com/posts/ensaios/america-nuestra. Consulta realizada em 29 de maio de 2015.

SILVA, Liliam R. (Re)contando a bistória: a (re)construção da identidade negra em Viva o Povo Brasileiro e Changó, el Gran Putas. Dissertação de Mestrado. Porto Alegre: PPG/LETRAS/ UFRGS, 2005. Página eletrônica: http://www.lume.ufrgs.br. Consulta realizada em 25 de janeiro de 2015.

\section{Anexo}

\section{Universidade Federal do Rio Grande do Sul}

\section{Instituto de Letras}

Pesquisa: Vozes Negras no Romance Hispano-americano

Coordenação: Profa. Me. Liliam Ramos da Silva

Contribuições são bem-vindas! Entre em contato liliam.ramos@ufrgs.br Lista preliminar de autores e obras

\section{Século XIX}

1 - Autobiografía de un esclavo (1835), de Juan Francisco Manzano (Cuba)

2 - Petrona y Rosalía (1838), de Félix Tanco y Bosmeniel (Colômbia)

3 - Francisco, el ingenio o las delicias del campo (1840), de Anselmo Suárez y Romero (Cuba) 
4 - La sibila de los Andes (1840), de Fermín Toro (Venezuela)

5 - Sab (1841), de Gertrudiz Gómez (Cuba)

6 - La marquesa de Yolombó (1845), de Tomás Carrasquilla (Colômbia)

7 - El Jíbaro: cuadro de costumbre de la isla de Puerto Rico (1849), de Manuel Alonso (Porto Rico)

8 - Historia del Perinclito Epaminondas del Cauca (1863), de Antonio Irrisari (Guatemala)

9 - Manuela (1867), de Eugenio Díaz (Colômbia)

10 - La campana de la tarde (1873), de Julio Rosas (Cuba)

11 - Florencio Conde (1875), de José María Samper (Colômbia)

12 - El negro Francisco (1880), de Antonio Zambrano (Cuba)

13 - Zarate (1882), de Eduardo Blanco (Venezuela)

14 - Cecilia Valdez (1882), de Cirilo Villaverde (Cuba)

15 - Carmela (1887), de Ramón Meza (Cuba)

16 - Sofia (1891), de Martín Morúa Delgado (Cuba)

17 - Romualdo, uno de tantos (1891), de Francisco Calcagno (Cuba)

\section{Século XX}

18 - Roque Moreno (1904), de Teresa González (Perú)

19 - El espejo y la ventana (1914), de Adalberto Ortiz (Equador)

20 - En este país (1916), de Manuel Urbaneja Alchepohl (Venezuela)

21 - Matalaché (1928), de Enrique López Albújar (Peru)

22 - Nochebuena negra (1930), de Juan Pablo Sojo (Venezuela)

23 - Ecue - Yamba - O (1933), de Alejo Carpentier (Cuba)

24 - Don Goyo (1933), de Demetrio Aguilera Malta (Equador)

25 - Canción de negros (1934), de Guillermo Meneses (Venezuela)

26 - Pobre negro (1937), de Romulo Gallegos (Venezuela)

27 - Las brujas de la mina (1938), de Gregorio Sanchez (Colômbia)

28 - Over (1939), de Ramón Marrero (República Dominicana)

29 - Juyungo (1942), de Adalberto Ortiz (Equador)

30 - El reino de este mundo (1949), de Alejo Carpentier (Cuba)

31 - Las estrelas son negras (1949), de Arnoldo Palacios (Colômbia)

32 - No give up, man! ¡No te rindas! (1959), de Hazel Robinsosn (Colômbia)

33 - Chambacú, corral de negros (1963), de Manuel Zapata Olivella (Colômbia) 
34 - Memorias de un cimarrón (1966), de Miguel Barnet (Cuba)

35 - Cuando la sangre se parece al fuego (1971), de Manuel Cofiño (Cuba)

36 - Yemanyá y Ochun (1980), de Lydia Cabrera (Cuba)

37 - Changó, el gran putas (1983), de Manuel Zapata Olivella (Colômbia)

38 - Historia de un joven negro (1983), de Juan Zapata Olivella (Colômbia)

39 - La tejedora de coronas (1984), de Germán Espinosa (Colômbia)

40 - Pisando el camino de ébano (1984), de Juan Zapata Olivella (Colômbia)

41 - Cincuenta testimonios (1985), de Juan Zapata Olivella (Colômbia)

42 - Tres mulatos de la revolución (1986), de Juan Zapata Olivella (Colômbia)

43 - Tambores para una canción perdida (1986), de Jorge Velasco Mackenzie (Equador)

44 - E1 monte (1989), de Lydia Cabrera (Cuba)

45 - Entre dos mundos (1990), de Juan Zapata Olivella (Colômbia)

46 - Una mujer sin raíces (1991), de Juan Zapata Olivella (Colômbia)

47 - Jonatás y Manuela (1994), de Luz Argentina Chiriboga (Equador)

48 - La balada de Johnny Sosa (1995), de Mario Delgado Aparain (Uruguai)

49 - Calypso (1996), de Tatiana Lobo (Costa Rica)

50 - Sexybondi (1999), de Washington Cucurto (Argentina)

51 - Josefa Nelú (1999), de Oralia Méndez Pérez (México)

52 - Tambores bajo mi piel, de Luz Argentina Chiriboga (Equador)

53 - 1810: La Revolución de Mayo vivida por los negros (2000), de Washington Cucurto (Argentina)

54 - María sigue siendo virgen (2000), de Francisco González (Colômbia)

\section{Século XXI}

55 - Cualquier miércoles soy tuya (2001), de Mayra Santos-Febres (Porto Rico)

56 - Las esclavas del rincón (2001), de Susana Cabrera (Uruguai)

57 - Malambo (2001), de Lucía Charún-Illescas (Peru)

58 - Cielo de tambores (2003), de Ana Gloria Moya (Argentina)

59 - Nuestra señora de la noche (2006), de Mayra Santos-Febres (Porto Rico)

60 - Echú y el viento (2006), de Teresa Cárdenas (Cuba)

61 - Tatanene cimarrón (2006), de Teresa Cárdenas (Cuba)

62 - Perro viejo (2006), de Teresa Cárdenas (Cuba)

63 - Cartas al cielo (2006), de Teresa Cárdenas (Cuba)

64 - Cosa de negros (2006), de Washington Cucurto (Argentina) 
65 - La máquina de hacer paraguayitos (2006), de Washington Cucurto (Argentina) 66 - La ceiba de la memoria (2007), de Roberto Burgos Cantor (Colômbia) 67 - Hasta quitarle Panamá a los yanquis (2007), de Washington Cucurto (Argentina) 68 - Fiebre negra (2008), de Miguel Rosenzvit (Argentina)

69 - Otilia Umaga, la mulata de Martinica (2009), de Lidia Barugel (Argentina)

70 - Fe en disfraz (2009), de Mayra Santos-Febres (Porto Rico)

71 - La isla bajo el mar (2009), de Isabel Allende (Chile)

72 - La nariz del diablo (2010), de Luz Argentina Chiriboga (Equador)

73 - Susurros negros (2010), de Mirta Fachini (Argentina)

74 - El negro Manuel (2011), de Tinco Andrada (Argentina)

75 - El espíritu oculto (2012), de Mirta Fachini (Argentina)

76 - Herencia negada (2013), de Mirta Fachini (Argentina) 